\title{
O DIREITO AO AFETO COMO DIREITO DA PERSONALIDADE
}

\author{
THE RIGHT TO AFFECTION AS A RIGHT OF PERSONALITY
}

Thiago Serrano Pinheiro de Souza*

RESUMO: O presente artigo tem por objetivo analisar a evolução do afeto como direito de personalidade no Estado Democrático de Direito, tendo por base a leitura conferida a tal valor fundamental, tanto pela doutrina quanto pela jurisprudência. A mencionada evolução será apresentada a partir da caracterização do valor afeto como efetivo direito de personalidade, e, para tanto, o trabalho partirá da conceituação daquilo que representa um determinado direito de personalidade, perpassando pelos conceitos de dignidade da pessoa humana, direito subjetivo e reparação do dano moral sofrido, até chegar à tutela e à conceituação do afeto no ordenamento jurídico brasileiro. Por fim, restará demonstrado o direito de personalidade ao afeto, tanto nas relações familiares quanto nas relações sociais.

PALAVRAS-CHAVE: Afeto. Direito de personalidade. Dignidade da pessoa humana.

ABSTRACT: This article aims to analyze the evolution of affection as a right of personality in a democratic state, based on the reading given to this fundamental value, both by doctrine and case law. The above developments will be presented from the characterization of the value affection as an effective right of personality, and both work part of the conceptualization of what constitutes a particular right personality, passing by the concepts of human dignity, subjective right and repair the damage moral suffering, to reach the protection and the conceptualization of affect in Brazilian legal system. Finally, there is shown the right personality to affect both family relations, and social relationships.

KEYWORDS: Affection. Right of personality. Dignity of the human person.

* Advogado. Especialista em Direito do Trabalho e Processo do Trabalho pela Escola de Magistratura do Trabalho do Estado do Rio de Janeiro. Professor de Direito Civil e de Prática Jurídica da Universidade Estácio de Sá. Mestrando em Direito Público e Evolução Social na linha de pesquisa Direitos Fundamentais e Novos Direitos da Universidade Estácio de Sá. E-mail: thiagoserrano@ymail.com 


\section{INTRODUÇ̃̃̃O}

O presente trabalho tem por base a constatação de que as relações humanas, bem como a relação do ser humano para consigo mesmo, são formadas por determinados atributos que constituem um ordenamento jurídico denominado direito da personalidade. Tais diversas dimensões da natureza humana são observadas e, posteriormente, normatizadas por meio de direitos subjetivos dentro do Estado Democrático de Direito. Na mencionada perspectiva, encontra-se o valor jurídico do afeto, como verdadeiro direito inerente à condição humana, decorrente da dignidade, e, por esta razão, devendo ser considerado direito fundamental.

O valor jurídico do afeto impõe uma pesquisa acadêmica detalhada, uma vez que juridicamente o presente valor vem sendo colocado em segundo plano, ante a impossibilidade de aferir claramente sua presença (ou sua ausência) nas relações humanas travadas socialmente. Os questionamentos acerca da responsabilização e da consequente reparação envolvendo relações desprovidas de amor alimentam o presente trabalho e constituem sua principal razão de existir.

Somente a partir da consolidação da ordem democrática, inaugurada pela Constituição Federal de 1988, é que, no Brasil, se construiu uma nova ideia acerca da tutela dos direitos de personalidade, muito mais adequada à dignidade da pessoa humana, que apresenta em seu conteúdo o afeto como verdadeiro valor jurídico, em um processo conhecido como repersonalização do direito.

Importante informar que a pesquisa desenvolvida girou em torno do pensamento de grandes juristas que desenvolveram estudos acerca do direito de personalidade, bem como do valor jurídico do afeto, sob diferentes perspectivas e enfoques. Com isso, o presente trabalho buscou compilar tais ideias e agregá-las de modo a fornecer ao meio acadêmico um texto coeso e didático.

Para tanto, o presente estudo inicia-se a partir das ideias de De Cupis acerca da conceituação e da tutela dos direitos de personalidade. Os autores Habermas, Rouland e Kelsen também foram citados para a determinação daquilo que se entende por direito subjetivo e por direito natural. E, dentro da caracterização dos direitos de personalidade no Brasil, o texto pautou-se nas lições de França e Gomes.

Ao se constatar que o valor afeto decorre do atributo da dignidade humana, o texto foi buscar fundamentação no imperativo categórico de Kant e nas concepções humanitárias de Bodin.

No que concerne à concepção e à conceituação do afeto como efetivo direito de personalidade, inúmeros autores foram citados. Daí o artigo, ao buscar a inserção do afeto no novo conceito de família, analisar as importantes lições de Dias, Sarmento, Brito, Melo e Andrighi. Na presente perspectiva, cumpre destacar os estudos de Supiot sobre a biologização do direito, bem como o pensamento de Kant acerca da prevalência do valor da dignidade humana em relação ao patrimônio. 
Além da inserção do afeto no direito de família, no presente artigo contata-se, também, a preocupação com a dimensão social do afeto. Com isso, o texto foi buscar na ética do cuidado de Boff e na ética da alteridade de Levinas os fundamentos necessários para a inserção proposta.

\section{DIREITO DA PERSONALIDADE: CONCEITO, CATEGORIA DE DIREITO SUBJETIVO, TESE POSITIVISTA E DIREITO NATURAL}

É possível afirmar que os primeiros direitos reconhecidos pelo ordenamento jurídico foram os de propriedade, e, a fim de salvaguardá-los, o positivismo cumpriu, em sua origem, o papel de impor a lei a setores impermeáveis e conservadores, mediante a obediência irrestrita ao seu primado. A partir da presente ideia (que se sustentava na consideração de que todos são iguais) a classe dominante à época (burguesia) pôde fortalecer seus elementos basilares, quais sejam: o patrimônio, o contrato e a autonomia da vontade. E nessa nova diagramação o cidadão passou a ser reconhecido como sujeito de direitos de propriedade, sem, no entanto, ter o reconhecimento da tutela de seus direitos de personalidade.

A lei adquire, dessa forma, o papel de instrumento viabilizador dos interesses burgueses. E, diante da presente perspectiva, Kelsen (1968 apud HABERMAS, 1997), defensor da autonomia científica do fenômeno jurídico, desengata o conceito do direito da moral. A separação entre sujeito de direito e pessoa moral abre o caminho da dogmática do direito para uma interpretação puramente funcionalista dos direitos subjetivos, nos quais se inserem os direitos patrimoniais. Observou-se que o liberalismo ortodoxo apenas renovou a compreensão reduzida dos direitos privados, provocando sua simples interpretação pragmática, que passa a ser moldura para o intercâmbio econômico capitalista à época.

O autor italiano De Cupis (2004, p.121), mais recentemente, criticou tal concepção, observando a configuração de interesses relacionados ao indivíduo, que são suscetíveis de proteção jurídica, e, de fato, são mais merecedores de tutela que os bens econômicos. Invertendo a visão clássica da sociedade civil, De Cupis vem, assim, colocar a pessoa humana no centro do universo jurídico. Em obra publicada em 1959, o autor construiu a unidade conceitual de situações jurídicas subjetivas acerca dos direitos de personalidade, em um momento de total ausência do direito privado em matéria de proteção dos direitos relacionados ao indivíduo, ainda como consequência do caráter patrimonial do ordenamento jurídico.

O Código Civil italiano de 1865 ignorava os direitos invioláveis do homem, bem como o faz o Código Civil italiano atual, que não contém uma seção dedicada aos direitos de personalidade, capitulando apenas o direito ao nome e alguns direitos de imagem. A mesma situação pode ser observada no Brasil, cujo Código Civil trata de forma superficial os direitos de personalidade, sem dispor acerca de uma cláusula geral de sua 
tutela. Ante a escassez legislativa, a doutrina passou a definir os direitos de personalidade como sendo uma categoria de direito subjetivo, orientada pelo modelo de direitos de propriedade sobre bens materiais.

A maioria dos autores brasileiros também entende que os direitos de personalidade constituem uma categoria de direito subjetivo, necessitando de tipificação de acordo com as diversas manifestações e aspectos da personalidade humana (atributos), a fim de salvaguardar a segurança jurídica e os limites de sua atuação. Em decorrência, inserem tais direitos no âmbito do direito privado, distinguindo-os dos direitos humanos. O presente fracionamento, porém, em diversos tipos é ilimitado e infinito, não havendo cientificismo algum nas diversas classificações doutrinárias.

Na visão de De Cupis, um determinado valor deve ser considerado como direito de personalidade, quando caracterizar um interesse autônomo e essencial da pessoa. Foi o mencionado autor o responsável pela construção, conceituação, delimitação e tutela dos direitos de personalidade, o que não o afastou, contudo, da ideia positivista. Assim, o autor italiano defendia a inserção de tais direitos dentro da órbita legislativa, sustentando que somente quando houver conflito entre valores autônomos e essenciais, a avaliação da prevalência de um ou de outro interesse deverá levar em conta a hierarquia dos valores constitucionais, como verificado por índices objetivos que emergem da lei, experiência doutrinária e jurisprudencial e, em última análise, da consciência social ${ }^{1}$.

Voltando para a realidade nacional, é possível afirmar que a doutrina brasileira encontra-se distante de uma leitura apropriada dos direitos de personalidade, fazendo tabula rasa ao fato de que a Constituição Federal de 1988 consagrou explicitamente a dignidade da pessoa humana, o que constitui verdadeira cláusula geral implícita de tutela dos direitos de personalidade ao lado de direitos especiais de personalidade consagrados em seu art. $5^{\circ}$ (SZANIAVWSKI, 2005, p. 228). Tal interpretação é, de certo, mais afinada à realidade dos direitos de personalidade e tem por mérito compatibilizar a perspectiva positivista com a efetiva tutela desses direitos.

Em outro polo, uma parte da doutrina brasileira defende a existência de uma cláusula geral implícita de tutela dos direitos de personalidade, que possibilita configurar determinados valores como efetivos direitos de personalidade, desde que protejam interesses essenciais e autônomos do ser humano. Nessa linha de raciocínio, França (1967, p. 389), por seu turno, entende que não é só a lei fonte do direito, mas também o costume e as conclusões da ciência jurídica. Assim, sustenta a aproximação dos direitos de personalidade com o direito natural, pois se trata de um direito que o ser humano possui para cumprir seu fim individual e social.

1 Neste sentido, DE CUPIS identifica "Il giudizio sulla prevalenza dell'uno o dell'altro interesse dovrà tenere conto della gerarchia dei valori constituzionali, verificata in base agli indici obiettivi Che emergono della legislazione, dall'esperienza dottrinaria e giurisprudenziale e, in ultima analisi, dalla coscienza sociale". 
Habermas (1997, p. 113), ao propor a reconstrução do sistema jurídico, a partir da formação discursiva da opinião e da vontade, define direito subjetivo como sendo o limite no interior do qual um sujeito pode empregar livremente a sua vontade. $\mathrm{O}$ direito moderno retira dos indivíduos, na visão do autor alemão, o fardo das normas morais e o transfere para as leis que garantem as liberdades de ação, cuja legitimidade, por seu turno, advém do processo legislativo, apoiado no princípio da soberania do povo, bem como no princípio do discurso.

Nessa esteira, percebe-se que os direitos de personalidade, ao serem considerados direitos subjetivos, não devem ser reduzidos à seara exclusivamente da moral, mesmo que sua raiz axiológica vincule-se à essência do ser humano. Segundo Habermas (1997, p. 113), a obtenção de uma teoria crítica da sociedade perpassa pela reconstrução da autocompreensão das ordens jurídicas modernas, com a redefinição do conceito de direito subjetivo. Assim, descola-o de uma perspectiva moral, a fim de investigar o aparente paradoxo existente no surgimento da legitimidade em decorrência da legalidade.

Criticando a premissa de que a autonomia privada merece ser protegida sob o ponto de vista da moral, Kelsen, como referido acima, desengata o direito da moral, uma vez que o sistema jurídico, ao se tornar inteiramente autônomo, tem que sobreviver com suas ficções autoproduzidas, introduzindo, assim, as pessoas naturais em seu próprio mundo circundante.

Fica claro que a doutrina moderna estabelece um corte bem claro entre direito e moral, sob a perspectiva do direito natural. Para Habermas (1997, p. 151), a indeterminação cognitiva, própria de quem age moralmente, é absorvida pelo o que pode ser feito em relação à normatização do direito. $O$ legislador decide quais normas valem como direito e os Tribunais resolvem, de forma razoável e definitiva, a disputa sobre a aplicação de normas válidas, porém carentes de interpretação.

Mais uma vez o traço distintivo entre direito e moral não poderá ser utilizado como simulacro a impedir a caracterização de interesses autônomos e essenciais do ser humano como efetivos direitos da personalidade. Dentro de uma fundamentação póstradicional, o indivíduo singular forma uma consciência moral dirigida por princípios e orienta seu agir pela ideia de autodeterminação, o que equivale, no âmbito da constituição de uma sociedade justa, a liberdade política do direito racional, isto é, da autolegislação democrática. Partindo da ideologia de que uma formação política racional da opinião e da vontade é possível, o princípio da democracia afirma como essa formação pode ser institucionalizada, e, assim, criando-se um sistema de direitos que garante a cada um igual participação num processo de normatização jurídica, proporcionando não apenas o procedimental, mas também o material de suas convicções.

O sistema jurídico retira das pessoas o poder de definição dos critérios de julgamento do que é justo ou injusto. O que significa um alívio para o indivíduo, que não precisa carregar o peso cognitivo da formação do juízo moral próprio, sob o ponto 
de vista da complementaridade entre direito e moral, do processo de legislação, da prática de decisão judicial institucionalizada e do trabalho profissional de uma dogmática jurídica, que sistematiza decisões e concretiza regras.

Sob outra perspectiva dialética, porém complementar, o antropólogo Rouland (2003, p. 235) afirma que os juristas romanos não hesitavam em definir fins ao direito, sendo o direito considerado a arte do bom e do equitativo, devendo atribuir a cada qual o que lhe é devido. No Ocidente, os teóricos do direito durante séculos afirmaram que um direito ideal, também chamado de direito natural, deveria guiar a busca dos bons sistemas de direito positivo.

A renúncia teórica do positivismo veio com a falta de acordo acerca do conteúdo do direito natural. Para Kelsen (apud ROULAND, 2003), em um segundo momento orientado pelo movimento racionalista, o direito é considerado apenas uma hierarquia de normas coercitivas indiferentes a qualquer consideração moral.

Porém, atualmente, segundo Rouland (2003, p. 236), não se pode basear apenas na decisão do legislador a licitude ou a proibição do divórcio, do aborto, das uniões homoafetivas, da equivalência ou da distinção entre filhos, dentre outras situações. Toda sociedade possui valores dominantes, que a experiência e a história confirmam ou invalidam, valores tais baseados em juízos morais.

\section{DIREITO DE PERSONALIDADE E DIGNIDADE DA PESSOA HUMANA}

É sabido que os princípios fundamentais, dispostos nos artigos $1^{\circ}$ a $4^{\circ}$ da Constituição Federal de 1988, representam o substrato fundamental de todo o sistema jurídico, estando dentre eles o princípio da dignidade da pessoa humana. Sob tal perspectiva, a dignidade humana pode ser conceituada como a norma maior que orienta o constitucionalismo contemporâneo, dotando-lhe de especial racionalidade, unidade, sentido e valor.

Da presente premissa constata-se a natureza axiológica da dignidade, uma vez que representa um valor constitucional fundamental, e mais, um verdadeiro atributo da personalidade humana, cujo valor espraia-se pelo complexo constitucional nutrindo o sistema, fornecendo o parâmetro de validade das demais normas integrantes e deduzindo a raiz antropológica que conduz o homem como pessoa, cidadão, trabalhador e administrado.

Buscando o diálogo entre direto de personalidade e dignidade humana, importante destacar a posição de Gomes (1966, p. 5). Para o mencionado autor, os direitos de personalidade possuem por escopo resguardar a dignidade da pessoa humana, preservando-a dos ataques que possa vir a sofrer por parte dos indivíduos, sendo essencial ao desenvolvimento do ser humano. Com isso, os atributos, as expressões ou projeções da personalidade humana consistem em objetos de direito de natureza especial que devem ser tutelados pelo ordenamento jurídico. 
A dignidade entendida como atributo essencial da pessoa humana não comporta possíveis afastamentos, como também não pode ser considerada como simples critério de interpretação constitucional. É, pois, efetiva norma dentro do processo denominado de densificação da norma constitucional, proposto por Canotilho (1993, p. 1127). A partir da presente ideia, pode-se afirmar que a dignidade humana possui intangível força normativa, consubstanciada por uma eficácia jurídica simétrica ou positiva, segundo Barcellos (2002, p. 61). Tal simetria decorre da perfeita identificação entre os efeitos desejados pela norma e a eficácia que lhe é reconhecida, como na imagem de dois triângulos simétricos opostos.

É cediço que a Constituição Federal de 1988 sustenta-se no princípio da dignidade da pessoa humana, princípio tal que nutre todo o ordenamento jurídico, inserindo-se em seu conteúdo o direito ao afeto, que clama por concretização. A desejada materialização possui como base deontológica o conceito de constituição dirigente proposto por Canotilho (2001, p. 102). Para o autor português, constituição dirigente é aquela em que o legislador atribui tarefas para o Estado e tenta modificar a sociedade por meio do direito. Em tal constituição, o legislador, por antecipação espiritual, tenta conformar a evolução social e formula os fins que devem pautar tal evolução.

Dentro da necessidade de concretização das normas constitucionais, destaca-se o posicionamento do Tribunal Constitucional alemão, que interliga a concretização ao processo de interpretação (Konkretizierung). A materialização não é igual à interpretação do texto da norma, entendido como o seu enunciado, mas sim a construção de uma verdadeira norma jurídica. Na acepção proposta, surge a dupla estrutura da linguagem em que o primeiro momento será o da compreensão, e o segundo será aquele em que o intérprete se depara com a questão de um modo prático no mundo (o acontecer do direito). Assim, tanto a compreensão da norma constitucional, como a sua concretização acontecem perante problemas concretos, inerentes ao ser relacional.

Na perspectiva do ser relacional insere-se a dignidade da pessoa humana, em seu viés afetivo, como instrumento hábil a determinar a essência dos seres humanos e seus padrões de conduta. Segundo Kant (apud BODIN, 2007), a dignidade compõe o imperativo categórico, decorrente da exigência de que o ser humano nunca seja visto como um meio para atingir outras finalidades, mas sim como um fim em si mesmo. Dessa forma, todas as normas oriundas da vontade legislativa precisam ter como finalidade o homem, sendo, pois, orientadas pelo valor básico, universal e incondicional da dignidade humana.

É por meio da ação e do discurso que os homens se comunicam uns com os outros, e se inserem no mundo humano. Dessa maneira, só o homem é capaz de comunicar a si próprio, e o afeto compõe um dos elementos possíveis da mencionada comunicação. Dentro da construção kantiana observa-se a dignidade como valor intrínseco às pessoas humanas. A humanidade, dentro da presente construção, é formada por seres racionais, 
dotados de livre arbítrio e de capacidade para interagir com os outros e com a natureza, sendo, nas palavras de Bodin (2007, p. 85), desumano tudo aquilo que puder reduzir a pessoa à condição de objeto.

Atualmente, o direito fraterno encontra-se ganhando significante espaço acadêmico, uma vez que também guarda, em sua conceituação, a premissa de que o homem é sujeito e não objeto da sociedade. A nova visão atribuída ao fenômeno jurídico é contrária a violência, o que fomenta o surgimento de um direito inclusivo, universal e, portanto, afetivo, pautado na dignidade humana. Segundo Resta (1992, p. 30), fraternal é o direito de compartilhar, mediante um pacto entre iguais, que possuem, dessa forma, a mesma dignidade. Para tanto, o sujeito deve ser reconhecido como livre e digno, a fim de ser considerado efetivo sujeito de direito, sendo que a sua liberdade só existe quando estiver vinculada a realização de uma escolha própria.

\section{DIREITO DE PERSONALIDADE E AFETO}

O ser humano é construído a partir de suas várias dimensões, quais sejam: família, vida social, patrimônio, dentre outras. Hodiernamente, tem-se entendido que todas essas dimensões são estruturadas por meio do valor jurídico afeto. Assim, o homem para ser digno necessita que o afeto seja reconhecido como valor inerente a sua condição humana e, dessa forma, um verdadeiro direito subjetivo de personalidade, que uma vez desrespeitado enseja reparação.

Partindo da premissa exposta acima, é possível visualizar a presença do valor afeto nas muitas manifestações humanas. Na construção de uma família, o afeto é imprescindível, tanto na relação intersubjetiva do casal ou dos pais quanto na relação desenvolvida destes para com sua prole. $\mathrm{O}$ afeto, ainda, pode ser encontrado nas relações sociais, pois sem ele o próprio Estado civilizado, calcado na perspectiva da repersonalização do direito, perderia um de seus fundamentos de existência e mergulharia na selvageria de outras épocas.

\subsection{O DIREITO AO AFETO COMO DIREITO DE PERSONALIDADE EM RELAÇÃO À FAMÍLIA}

Dentro da concepção acerca do afeto como direito de personalidade em relação à família, é possível visualizar sua importância nas palavras de Dias (2011, p. 336):

O direito das famílias, ao receber o influxo do direito constitucional, foi alvo de uma profunda transformação. O princípio da igualdade ocasionou uma verdadeira revolução ao banir as discriminações que existiam no campo das relações familiares. Num único dispositivo, o constituinte espancou séculos de hipocrisia e preconceito. Além de alargar o conceito de família para além do casamento, foi derrogada toda a legislação que hierarquizava homens e mulheres, bem como a que estabelecia diferenciações entre os filhos pelo vínculo existente 
entre os pais. A Constituição Federal, ao outorgar a proteção à família, independentemente da celebração do casamento, vincou um novo conceito, o de entidade familiar, albergando vínculos afetivos outros.

A partir do texto mencionado é possível perceber a vinculação que a doutrinadora faz entre direito civil e direito constitucional, dentro da leitura civil-constitucional do ordenamento jurídico brasileiro. Na perspectiva apresentada, o princípio da isonomia ganhou caráter normativo, fazendo com que uma nova ideologia acerca de família surgisse: a família constituída por meio do afeto. Tornou-se irrelevante perquirir se a família foi formada por meio do casamento, da união estável, de um simples namoro, de uma parceria entre pessoas do mesmo sexo ou da adoção realizada por uma pessoa solteira. Neste sentido, o direito à afetividade ou ao afeto é um direito de personalidade no tocante à estruturação da entidade familiar.

O que se percebe é o desvínculo a um formalismo exacerbado que segregava socialmente alguns indivíduos. Não subsistem, dessa maneira, hierarquia entre filhos, distinções entre sexos ou preconceitos de qualquer espécie. O sujeito, a partir da nova perspectiva relatada, passou a escolher a forma de constituir sua família, sendo tal escolha sempre pautada no afeto.

Sarmento (2008, p. 643), nessa linha de raciocínio, entende que o afeto representa um dos fundamentos mais significativos da família moderna, indo além de uma dimensão ética, pois é considerado como verdadeiro valor jurídico de perfil constitucional²:

Enfim, se a nota essencial das entidades familiares no novo paradigma introduzido pela Constituição Federal de 1988 é a valorização do afeto, não há razão alguma para exclusão das parcerias homossexuais, que podem caracterizar-se pela mesma comunhão e profundidade de sentimentos presentes no casamento ou na união estável entre pessoas de sexos opostos, não existindo, portanto, qualquer justificativa legítima para a discriminação praticada contra os homossexuais.

O citado constitucionalista, ao enaltecer o afeto e considerá-lo como elemento estruturante da entidade familiar, reconhece sua presença nas parcerias homossexuais. Na presente perspectiva, o que determina o conceito de família é o afeto, encontrado nas relações havidas entre pessoas do mesmo sexo ou de sexos opostos, e em respeito ao princípio da não discriminação - corolário do princípio da isonomia -, exige-se do ordenamento tratamento igualitário.

$\mathrm{Na}$ presente ordem de ideias, a fim materializar as promessas contidas na Constituição Federal de 1988, a jurisprudência possui papel de destaque na tutela do direito ao afeto, diante das relações familiares.

2 Nesse sentido, Sarmento justifica a inaplicabilidade do art. 226, parágrafo $3^{\circ}$ da CRFB sob o argumento de que a Constituição deve ser interpretada como um sistema aberto ordenado, o que materializa um princípio dos mais importantes, qual seja, o da unidade constitucional. 
No Recurso Extraordinário n. ${ }^{\circ} 47554$ de Minas Gerais, relatado pelo Ministro Ayres Brito e julgado em 05 de Maio de 2011, foi reconhecido o direito de casais homossexuais constituírem família sob a égide do direito. Nesse julgamento histórico, o Supremo Tribunal Federal entendeu que o afeto é um valor jurídico impregnado de natureza constitucional, a partir de um novo paradigma da entidade familiar, qual seja, o direito à busca da felicidade.

Assim, a busca pela felicidade se torna, no ordenamento brasileiro, um verdadeiro postulado constitucional implícito, sendo que a expressão da presente ideia-força deriva do princípio da dignidade da pessoa humana. Para o Supremo Tribunal Federal, não há dignidade humana sem felicidade, e, com base na presente fórmula, não há felicidade sem o reconhecimento da existência de famílias formadas por casais homossexuais.

O STF, por meio do voto do Ministro Celso de Melo, materializou a plena realização dos valores da liberdade e da igualdade - em sua vertente de não discriminação - que representam fundamentos essenciais à configuração de uma sociedade que se quer democrática. No sentido de conferir realidade fática e efetiva a comandos constitucionais, o Supremo respeitou o princípio da isonomia, assegurando a observância da autonomia individual em relação à orientação sexual, a partir da primazia da dignidade da pessoa humana.

Como visto, a jurisprudência possui papel de destaque no aprimoramento dos direitos de personalidade, mediante entendimentos consubstanciados nos casos concretos submetidos à apreciação pelos Tribunais. É ela que soluciona tão difícil tarefa, já que encarregada tanto da aplicação da lei no cotidiano social quanto da reparação do dano sofrido.

Apesar de a jurisprudência ainda não reconhecer de forma unânime a existência de uma cláusula geral de proteção da personalidade humana implícita na Constituição Federal de 1988, e, também, da ausência de uma teoria acerca da tutela dos direitos de personalidade no Brasil, alguns direitos especiais de personalidade vêm sendo tutelados de forma satisfatória.

Cumpre mencionar que, no direito brasileiro, a tutela da personalidade humana iniciou-se no âmbito criminal, buscando às vítimas proteção penal quando da violação de seus direitos de personalidade. Tal fato decorreu da injustificável resistência que os Tribunais brasileiros mantiveram durante décadas em reconhecer o ressarcimento do dano moral. Nessa esteira, o que se visualiza é uma modificação significativa de pensamento, como é percebido em recentes decisões comentadas a seguir.

$\mathrm{O}$ desrespeito ao afeto nas relações intersubjetivas acarreta em um efetivo dano à pessoa humana. Um pai que não dá afeto a seu filho, mesmo pagando-lhe todas as despesas, comete um dano, ao menos, de ordem moral (para aqueles que entendem que o afeto não constitui um verdadeiro valor constitucional), passível de reparação de caráter patrimonial. Assim, é possível constatar, a partir da premissa disposta, que existem 
situações não contempladas pelo ordenamento jurídico que causam danos. Alguns até diriam, de forma inapropriada, que no presente caso o pai, que paga as despesas do filho e não lhe dá afeto, causa um dano que não geraria responsabilização.

Daí a tarefa da jurisprudência ser difícil. Os Tribunais necessitam de amparo jurídico para ressarcir tal dano, ou seja, o dano causado por um pai que não dá afeto ao filho, mesmo pagando pensão alimentícia ou arcando com suas despesas. A partir do pensamento de Gomes (1966, p. 5), é possível construir a presente fundamentação, pois, para o mencionado autor, nas últimas décadas houve a mudança conceitual do ato ilícito para o dano injusto. $\mathrm{O}$ dano será considerado injusto quando afetar aspecto essencial da dignidade humana, mesmo não sendo antijurídico. Caso a vítima, ponderados os interesses, permanecer irressarcida, cumpre aplicar o conceito de dano injusto, em respeito ao princípio basilar da responsabilidade civil moderna, ou seja, a vítima não pode ficar irressarcida.

Na presente análise cabe à jurisprudência ressaltar a ocorrência da injustiça do dano, o que o torna indenizável e reparável. Dessa forma, a lesão que acarreta o dano vincula-se ao bem jurídico merecedor de tutela, qual seja, o afeto.

Já no Recurso Especial n. ${ }^{\circ} 1000356$ de São Paulo, julgado em 25 de maio de 2010, o Superior Tribunal de Justiça, por meio da relatoria da Ministra Nancy Andrighi, entendeu haver o direito à afetividade naquele determinado caso concreto, o que impediu a declaração de nulidade do registro de nascimento, em que ficou biologicamente provado que a filiação era meramente afetiva:

Adoção à brasileira. Vínculo constituído por meio da convivência e do afeto. Desconsideração da verdade genética e da formalidade. Proteção integral à criança. Direito à afetividade. Mantém-se o acórdão impugnado, impondo-se a irrevogabilidade do reconhecimento voluntário da maternidade, por força da ausência de vício na manifestação da vontade, ainda que procedida em descompasso com a verdade biológica. Isso porque prevalece, na hipótese, a ligação sócio-afetiva construída e consolidada entre mãe e filha, que tem proteção indelével conferida à personalidade humana, por meio da cláusula geral que a tutela e encontra respaldo na preservação da estabilidade familiar. Recurso especial não provido. (Grifo nossos).

Na presente decisão é possível extrair o entendimento pelo reconhecimento da existência de uma cláusula geral de tutela dos direitos de personalidade pelo Superior Tribunal de Justiça. Como mencionado acima, para alguns juristas, tal cláusula pode ser encontrada em nosso ordenamento, como decorrência do princípio da dignidade da pessoa humana. Dessa maneira, tudo aquilo que representar um interesse autônomo e essencial do indivíduo deve ser considerado direito de personalidade, e, por via de consequência, deve estar albergado pela mencionada cláusula. Nesse sentido, o direito à afetividade ou ao afeto é um direito de personalidade no tocante à preservação da entidade familiar. 
Segundo o Superior Tribunal de Justiça, ao analisar as lides que apresentam contornos afetivos, o juiz deve estar atento às peculiaridades apresentadas em cada caso concreto, e decidir com base na dignidade humana, na solidariedade, na afetividade, na busca pela felicidade, na liberdade, na igualdade e no princípio da eticidade.

Ainda, para Andrighi, o que deve balizar o conceito de família é, sobretudo, o princípio da afetividade, que fundamenta o direito familiar na estabilidade das relações socioafetivas e na comunhão de vida, com primazia sobre as considerações de caráter patrimonial ou biológico.

Importante destacar que no presente entendimento o afeto consubstancia a preservação da entidade familiar. Tal preservação é, assim, reconhecida como um interesse inalienável do indivíduo, que necessita de um núcleo estável para evoluir como ser humano. E, dessa forma, caberá ao direito tutelar o presente direito de personalidade, já que, como visto, faz parte do patrimônio mínimo existencial decorrente da dignidade humana.

Diante da repersonalização do direito o ser humano é colocado no centro do universo jurídico, sendo considerada mais importante a sua tutela do que a de seu patrimônio. Segundo Kant (apud BODIN, 2007), na sociedade é possível identificar duas categorias de valores, quais sejam, o preço e a dignidade; o primeiro representa um valor exterior patrimonial, já a segunda representa um valor interior moral. Dessa forma, enquanto o preço vincula-se a interesses particulares, a dignidade vincula-se ao interesse geral, merecendo uma tutela infinitamente maior em comparação com o patrimônio. Tal tutela configura-se mais importante ao se pensar que o valor moral não admite ser substituído por equivalente, enquanto a mercadoria, sim.

Dentro da discussão acerca de a verdade biológica não ser decisiva para a solução de determinada questão, cumpre relatar a visão de Supiot. Para o mencionado autor, o direito assume um papel dogmático de interpretação e de proibição. Dessa forma, o ramo jurídico exerce uma função singular dentre as técnicas existentes, pois é considerado como uma verdadeira técnica de humanização das relações sociais.

Segundo Supiot (2007, p. 178):

\begin{abstract}
A biologização do direito civil tem efeitos destrutivos que não são imediatamente perceptíveis como puderam ser as devastações da industrialização sobre o estado físico da classe operária. Nenhuma classe social está aqui especialmente envolvida, pois não é a constituição física dos operários, mas o equilíbrio psíquico dos indivíduos que está ameaçado por uma redução da identidade humana a uma suposta verdade biológica.
\end{abstract}

O direito é, assim, considerado uma técnica de humanização, não podendo ficar restrito a uma verdade biológica desprovida de profunda análise dos contornos afetivos do caso concreto sob exame. 


\subsection{O DIREITO AO AFETO COMO DIREITO DE PERSONALIDADE EM RELAÇÃO À VIDA SOCIAL}

Esgotadas as considerações acerca do afeto como direito de personalidade em relação à família, importante se faz a análise do afeto como direito de personalidade em relação à vida social.

Dentro da conceituação relativa à ética do cuidado encontra-se o sentido social do afeto. Para Boff (1999), a ética do cuidado é um consenso mínimo a partir do qual o indivíduo pode se amparar e elaborar uma atitude cuidadosa, protetora e amorosa para com a realidade em que vive, sendo que tal afeto vibra diante da vida ao protegêla e expandi-la. Os mais céticos poderiam dizer que não há como efetivar o presente pleito dentro de uma sociedade como a atual, em que o individualismo continua possuindo importância para o sistema consagrado.

Porém, o próprio Boff, complementando a ética do cuidado, conceitua a ética da responsabilidade, que determina um padrão comportamental. Assim, o indivíduo deve agir de maneira que sua ação não seja destrutiva, e sim benevolente, cabendo a ele conservar, expandir e irradiar a vida, e o desrespeito a tais premissas acarretaria a responsabilização do sujeito e a consequente reparação do dano. A solidariedade, por fim, seria o elo final que vincularia a ética do cuidado à ética da responsabilidade, fazendo com que seja alcançado um patamar mínimo de comportamento, cujos valores sejam humanitários.

De acordo com Bodin (2007), o princípio da solidariedade social é previsto constitucionalmente, substituindo a perspectiva individualista garantida pela legislação infraconstitucional. Dessa sorte, é possível constatar a solidariedade em seu aspecto social e, também, em seu aspecto jurídico, ambos orientados pelo afeto. Com isso, as pessoas e os grupos sociais têm o direito a ser iguais quando a diferença os inferioriza, e o direito de ser diferentes quando a igualdade os descaracteriza.

A solidariedade está consubstanciada na premissa exposta acima, pois se todos fossem iguais não haveria necessidade de se utilizar o afeto para lapidar comportamentos. O que o direito faz é possibilitar a coexistência pacífica das diversas concepções de vida, a partir de suas peculiaridades, em respeito à dignidade humana, que é universal.

Filosoficamente, a pluralidade humana é considerada a paradoxal pluralidade de seres singulares, uma vez que, se fossem diferentes, os homens não seriam capazes de compreender-se entre si e aos seus ancestrais, nem de prever as necessidades das gerações futuras, e, de outra sorte, se fossem iguais, os homens dispensariam o discurso ou a ação para se fazerem entender, pois com simples sinais poderiam comunicar suas necessidades imediatas e idênticas. $\mathrm{O}$ afeto social busca exatamente mediar as possíveis tensões existentes na estruturação da vida do ser relacional, diante da paradoxal pluralidade apontada pela filosofia. 
A necessidade de respeito pelo outro também pode ser visualizada, sob diferente perspectiva, no pensamento de Levinas, por meio da ética da alteridade. $\mathrm{O}$ autor percebeu que o pensamento ocidental, a partir da filosofia grega, desenvolveu-se como discurso de dominação. O ser dominou a Antiguidade e a Idade Média, sendo depois substituído pelo eu desde a época moderna até os nossos dias, porém sempre sob a mesma premissa, qual seja, a unidade unificadora e totalizante que exclui o confronto e a valorização da diversidade, entendida como abertura para o outro.

Segundo Levinas (apud RODRIGUES, 2011):

O Outro metafísico é outro de uma alteridade que não é formal, de uma alteridade que não é um simples inverso da identidade, nem de uma alteridade feita de resistência ao Mesmo, mas de uma alteridade anterior a toda a iniciativa, a todo o imperialismo do Mesmo; outro de uma alteridade que não limita o Mesmo, porque nesse caso o Outro não seria rigorosamente Outro: pela comunidade da fronteira, seria, dentro do sistema, ainda o Mesmo. O absolutamente Outro é Outrem; não faz número comigo. A coletividade em que eu digo tu ou nós não é um plural de $e u$. Eu, tu, não são indivíduos de um conceito comum.

Levinas analisa a relação de responsabilidade pelo outrem, no sentido de estar frente a frente, como resultado da reunião humana no mundo social, o que se expressa no seu conceito de rosto. Dessa forma, o autor afirma que esse estar frente a frente é um acesso ao rosto, que, em princípio, é ético. A partir de tal construção, quando o eu se vê frente a frente com o outro, acaba se tornando responsável por ele.

É possível afirmar que, para o autor, a ética é a filosofia original, que desde o início orienta-se para o outro. Tratando da ética da alteridade como filosofia primeira, exige-se que o encontro ou a comunhão aconteça no respeito à alteridade do outro, pois, como observado no texto reproduzido acima, o existir requer que o outro mantenha-se em si mesmo. Aqui há uma redundância de Levinas explicada pela ênfase que o autor fornece para a qualidade do que é do outro, ao mencionar alteridade do outro. $\mathrm{O}$ outro, nesse contexto, deve ser considerado como parte imodificável do mesmo.

Por fim, cabe mencionar que o Cristianismo, em sua origem, afirmava que o homem, embora dotado de vontade livre, tem o primeiro impulso direcionado para transgressão, em decorrência da natureza humana fraca e pecadora. Dessa maneira, o ser humano seria incapaz de realizar o bem, necessitando da ajuda de Deus para tanto. Daí a importância da conduta moral, que orientou a edição de normas e regras impostas pelo dever, ante a incapacidade humana em respeitar a alteridade do outro.

Importante destacar que o dever, segundo Kant (apud BODIN, 2007), não se apresenta por meio de conteúdos fixos, nem tampouco é uma lista de virtudes, pois antes se configura por meio de uma forma que deve valer para toda ação moral (e aqui se faz uma ressalva ao entendimento de Habermas, acerca da desvinculação entre direito e moral, como mencionado acima). É dentro do imperativo categórico, já relatado anteriormente, que surge a dignidade não como um meio e sim como um fim: o homem. 


\section{CONCLUSÃO}

A par de todas as informações compiladas no decorrer do presente artigo, é de se concluir que o afeto constitui um verdadeiro direito de personalidade, já que representa um interesse autônomo e essencial do ser humano, independentemente de norma preexistente que o discipline.

É imperioso afirmar que para parte da doutrina brasileira a existência de uma cláusula geral implícita de tutela dos direitos de personalidade possibilita configurar determinados valores como efetivos direitos de personalidade, desde que protejam interesses do ser humano vinculados a sua dignidade. E, assim, os direitos de personalidade podem ser considerados um refinamento normativo com o objetivo de tutelar a dignidade humana, já que se exige o preenchimento de seu contorno.

As relações humanas devem pautar-se no afeto, em respeito ao atributo da dignidade, que possui amparo constitucional e necessidade de concretização no Estado Democrático de Direito. E, de outra sorte, considera-se afeto a conduta amorosa estabelecida entre os indivíduos em sede familiar, social, cível, trabalhista, dentre outras.

Retornando aos autores citados, é possível constatar que para De Cupis os direitos de personalidade são direitos subjetivos que têm origem em valores autônomos e essenciais ao homem, mas que para a sua tutela necessitam ser carreados para o ordenamento jurídico. De outra sorte, França, dentre os brasileiros, desvincula-se do primado da lei e aproxima os direitos de personalidade do direito natural.

Como relatado em linhas anteriores, Habermas propõe um corte entre direito e moral, já que o sujeito não deve suportar o fardo do peso cognitivo da formação do juízo moral próprio, que deve ficar na lei, elaborada pela formação discursiva da opinião e da vontade. Para o autor, o direito às liberdades de ação subjetivas, como direito moral, não pode ser simplesmente imposto ao legislador como barreira exterior, nem instrumentalizado como requisto funcional para seus objetivos (como proposto por Kelsen), devendo, pois, ser institucionalizado juridicamente, pela teoria do discurso, que ensina serem os destinatários simultaneamente os autores de seus direitos.

Já para Rouland, o direito precisa conter juízos de valores encontrados na formação moral de cada sociedade. $\mathrm{O}$ autor preocupa-se com o respeito aos valores construídos por cada sociedade, independentemente do fato de se encontrarem ou não positivados. O homem, segundo o antropólogo francês, caracteriza-se por uma série de invariantes, fazendo da ideia de direitos do homem legítima. Assim, o homem só realiza as invariantes de que é portador no seio de sociedades concretas, datadas e localizadas, sujeitas, como à humanidade, a morte. E elas são mais do que a soma de indivíduos, pois formam totalidades culturais, que, por seu turno, precisam ser respeitadas e reconhecidas.

Diante da análise de diferentes e abalizadas opiniões, é possível defender que o jurista tem um papel de destaque, que não é somente validar a opinião dos vencedores 
naquele dado momento. A recusa de um juízo de valores pode ser condenável, na medida em que pode justificar a arbitrariedade, normalizar os comportamentos criticáveis e, até mesmo, deixar de materializar promessas constitucionais, uma vez que o jurista não é escravo da lei.

Não há dúvidas de que o afeto seja um direito de personalidade, porém foi relevante conhecer quais são os interesses autônomos e essenciais a serem protegidos. A partir disso, o presente trabalho desenvolveu uma pesquisa sobre o afeto dentro das relações familiares e das relações sociais.

O novo conceito de família proposto preocupa-se muito mais com o afeto do que com o patrimônio, e, até mesmo, com a verdade biológica. Nesse processo denominado repersonalização do direito, o ser humano efetivamente passa a constituir o centro do universo jurídico, consubstanciando o atributo da dignidade da pessoa humana. Cumpre destacar, que a própria entidade familiar tem como um de seus principais pilares o afeto, tanto na determinação de sua formação quanto nas relações intersubjetivas desenvolvidas por seus membros, bem como na preservação de sua unidade.

Dessa maneira, o afeto deve ser considerado e reconhecido como valor jurídico constitucional, viabilizando a dignidade ao romper paradigmas históricos, culturais e sociais, permitindo que as escolhas pautadas no amor se sobreponham ao formalismo exacerbado de outras épocas, em respeito à igualdade e à busca pela felicidade.

Dentro da perspectiva social do afeto, é necessário pontuar que o homem precisa ter um comportamento afetivo em relação ao outro ao se inserir em sociedade. $O$ presente interesse é, também, considerado essencial para o indivíduo, o que o caracteriza como direito de personalidade. Assim, uma atitude de cuidado, proteção e amor para com o próximo deve ser tutelada pelo ordenamento jurídico, cabendo reparação pelo seu descumprimento.

Por fim, o direito ao afeto pode ser cogitado em um mundo social que se quer formado pela diversidade. $\mathrm{O}$ respeito à diversidade não pode ser visto como algo meramente formal, por meio de normas ineficazes e frias. Ao contrário, o respeito à diversidade perpassa pelo fato de não ver o outro como outro em si, mas sim como parte do mesmo. A subjetividade, no presente contexto, precisa acolher a diferença como pressuposto da elaboração de um discurso e de uma efetivação ética e inclusiva, a partir de uma análise antropológica do homem.

\section{REFERÊNCIAS}

BARCELLOS, Ana Paula de. A eficácia jurídica dos princípios constitucionais - o princípio da dignidade da pessoa humana. Renovar: Rio de Janeiro, 2002.

BIANCA, Massino. Il diritto alla riservatezza, in valore dela persona e guistizia contratuale, scritti in onore di Adriano de Cupis. Milano: Doot.A.Giuffré Editore, 2005. 
BOFF, Leonardo. Saber cuidar: ética do humano. Petrópolis: Vozes, 1999.

CANOTILHO, J. J. Gomes. Constituição dirigente e vinculação do legislador - contributo para compreensão das normas programáticas. Coimbra: Coimbra Editora, 2001.

CANOTILHO, J. J. Gomes. Direito constitucional. 6.ed. revista. Coimbra: Almedina, 1993.

DE CUPIS, Adriano. Os direitos da personalidade. Campinas: Romana Jurídica, 2004.

DIAS, Maria Berenice. Diversidade sexual e direito homoafetivo. São Paulo: Revista dos Tribunais, 2011.

FRANÇA, Limongi. Direitos privados da personalidade. Revista Forense, Rio de Janeiro, v. 217, p. 389, fev. 1967.

GOMES, Orlando. Direitos da personalidade. Revista Forense, Rio de Janeiro, v. 216, p. 5, 1966.

HABERMAS, Jurguen. Direito e democracia: entre facticidade e validade. v. I. Tradução de Flávio Beno Siebeneichler. Rio de Janeiro: Tempo Brasileiro, 1997.

MORAES, Maria Celina Bodin. Danos à pessoa: uma leitura civil-constitucional dos danos morais. Rio de Janeiro: Renovar, 2007, $3^{\text {a }}$ Tiragem.

PIOVESAN, Flávia. Temas de direitos humanos. São Paulo: Max Limonad, 2003.

RODRIGUES, Ricardo Antonio e outros. A alteridade como fundamento da ética levinasiana.

Disponível em < www.ufsm.br/gpforma/2senafe/PDF/018e3.pdf>. Acessado em novembro 2011.

ROULAND, Norbert. Nos confins do direito: antropologia jurídica da modernidade. Tradução de Maria Ermantina de Almeida Prado Galvão. São Paulo: Martins Fontes, 2003.

SARMENTO, Daniel. Casamento e união estável entre pessoas do mesmo sexo: perspectivas constitucionais, in Igualdade, diferença e direitos humanos. Rio de Janeiro: Lumen Juris, 2008.

SUPIOT, Alain. Homo juridicus: ensaio sobre a função antropológica do direito. Tradução de Maria Ermantina de Almeida Prado Galvão. São Paulo: Martins Fontes, 2007.

SZANIAVWSKI, Elimar. Direitos de personalidade e sua tutela. São Paulo: RT, 2005. 